\section{Evaluating cancer therapies}

\section{Washington}

AFTER years of fighting with the insurance industry over the support of clinical trials, cancer researchers are moving to take matters into their own hands. Rather than continuing to bias their research towards those drugs and techniques that insurance companies will pay for patients to receive neglecting promising therapies - members of the American Society of Clinical Oncology (ASCO) are planning to set up an independent evaluation panel in hopes of bringing insurance support in line with scientific consensus.

The panel, loosely modelled after the congressional Office of Technology Assessment, is expected to review both experimental and established drugs and techniques, evaluating what is known about their efficacy and listing appropriate circumstances for their use.

Researchers hope that such a panel can separate promising therapies from longshots - and weed out expensive treatments that are no longer the state of the art.

"We're looking at new and expensive technology," says Martin Abeloff, ASCO president and clinical director of the Johns Hopkins University Oncology Center in Baltimore. "But we're also hoping to show that the medical community can do some policing of itself, that it can abandon therapies it no longer considers useful." If so, it may help solve one of the principal problems in clinical cancer research: patient costs. Because most government research grants do not generally include money for patient care costs (on the assumption that insurance companies would have to pay for patients' care whether they are in or out of a clinical trial), researchers are dependent on the insurers to cover all but the direct research costs.

If insurance companies decide that the treatments are "experimental" or "investigational" rather than "generally accepted" as a treatment option, they often will not support them on the grounds that unproven and expensive therapies are usually not in the best interests of the patients. If an insurance company has $\$ 150,000$ to spend on a breast cancer patient's care, they ask, should that go to one experimental autologous bone marrow transplant (ABMT), or to a dozen less extreme - and better understood measures? In recent years, as insurance companies found their resources strained by rising health care costs, the default position has been to support no investigative therapies, except under pressure from the courts. Not surprisingly, that has made life difficult for cancer researchers, who have in some cases been forced to postpone trials on promising, but unconfirmed, drugs when their trial participants could not get insurance support.

For example, Larry Norton, chief of breast cancer residency at Memorial Sloan Kettering Hospital in New York, says his research on taxol, an experimental compound extracted from the bark of the Pacific Yew tree, has been delayed because about half of the participants in his trials are refused insurance coverage. He is forced to recruit twice as many participants as he needs, a process that can take months.

But Norton, like many other researchers, does not blame the insurance companies for with no heroes and no villains," he says. The companies are usually trying to get the most effective care for their money, he points out. But when they are confronted with something like an ABMT, they are put in a quandary.

At something on the order of $\$ 150,000$ a her bone marrow removed, is given massive chemotherapy treatments, and then has the marrow returned - are tremendously expensive. For most breast cancer patients, an ABMT is unlikely to work better than chemotherapy alone. Even in the small percentage of patients where ABMTs are considered a good bet, no one knows how effective they are in eradicating cancer for good; few patients have been followed for more than a year or two.

Overall, researchers say, ABMTs are probably only effective in a few per cent of breast cancer cases.

When insurance companies decide not to support an ABMT for a patient, they usually cite experts who say that the treatment is still unproven and "investigational". Sometimes that is the end of the line for the patient. But, increasingly, patients are taking the companies to court and winning. Of 15 cases last year, 13 were decided in favour of the patient. Few judges want to deny a cancer victim any chance - no matter how slim for recovery. If ABMTs really are an effective treatment, compared to other therapies, then this is all for the best. But if they are not as effective as some practitioners claim, and sap scarce treatment dollars that could be used in more promising trials, ABMTs could be slowing the progress of cancer research.

This is the sort of issue that ASCO hopes its panel can address. Abeloff says that ABMTs may be used as a trial balloon to gauge the ability of the panel to reach consensus and the response of the insurance industry.

So far, the industry seems enthusiastic. "We would very much encourage this," says James Cross, medical director for claim operations for the Travelers Companies, a major health insurance group. "It is very difficult for us as insurers to know what the state of the art really is." But he cautions that the panel must be careful not to stamp every new therapy with a seal of approval. "It will be very important for ASCO to do it well and to be very critical, to take a good look and not just a superficial examination. If they err on his troubles. "It's a complicated problem treatment, ABMTs - in which a patient has the side of approving everything, it won't have the same validity." Travelers has set up assessment panels of its own, assembled from researchers from well regarded hospitals and research centres.

But such expert panels are no guarantee in court, where judges are confronted with often contradictory expert testimony. Were an independent group with the backing of a professional society like ASCO to decide that ABMTs are still "investigative" rather than accepted, courts might give it more weight.

Beyond ABMTs, candidate therapies for ASCO assessment include taxol and colony stimulating factor. The panel may also examine "off-label" drug uses - drugs that have Food and Drug Administration (FDA) approval for treating one disease, but may be useful for another disease, or in combination with other drugs. In all, about half of chemotherapy drugs have uses beyond those for which they were approved. But many insurers will not pay for any off-label use, even as part of an approved clinical trial. For instance, researchers have found that carboplatin (which was originally approved for ovarian cancer) may be even more useful in treating small cell lung cancer, but many insurance companies still refuse to pay for this use.

Next step for ASCO is a report this fall from an ad hoc committee that is studying how to set up such an assessment panel.

If all goes well, the panel could be up and running some time next year.

This week the issue will come before Congress, when Senator Brock Adams (Democrat, Washington) chairs a hearing on breast cancer therapies and insurance industry support problems. SCIENTIFIC MISCONDUCT Conflict in
NIH pane!

\section{Washington}

CHARGING conflict of interest, the NIH have asked one of the members of the panel investigating Thereza Imanishi-Kari to resign.

University of Chicago immunologist Ursula Storb wrote a letter of recommendation for Imanishi-Kari in 1986, NIH found, but did not disclose that fact when she was asked to join the investigative panel. Storb was one of two panel members who wrote a dissenting opinion earlier this year when the NIH panel concluded that Imanishi-Kari had fabricated much of the data in a 1986 Cell paper. Storb told the New York Times, which reported the charge last week, that she had forgotten about the job recommendation. Even if she had remembered, she said, she would not have raised it because she did not consider such a relationship to be a conflict of interest. She has declined to resign. 